\title{
Self-ownership, abortion and infanticide
}

\author{
Ellen Frankel Paul Department of Political Science, Miami University, Oxford, Ohio \\ Jeffrey Paul Department of Philosophy, Northern Kentucky University, Kentucky
}

\begin{abstract}
Authors' abstract
Doctors have been placed in an anomalous position by abortion laws which sanction the termination of a fetus while in a woman's womb, yet call it murder when a physician attempts to end the life of a fetus which has somehow survived such a procedure. This predicament, the doctors' dilemma, can be resolved by adopting a strategy which posits the right to ownership of one's own body for human beings. Such an approach will generate a consistent policy prescription, one that sanctions the right of all pregnant women to abortions, yet grants the fetus, after it becomes viable as a potentially independent person, a right to its own body. The doctors' dilemma is surmounted, then, by requiring that abortions of viable fetuses be performed in a manner that will produce a live delivery. Hence, infanticide and termination of viable fetuses are proscribed.
\end{abstract}

\section{Introduction}

Recently, an intriguing case has come to trial which poses both a moral and legal dilemma for those who would argue for the permissibility of abortions. ${ }^{1}$ A California doctor was accused of strangling to death a surviving baby girl after a legal saline abortion. The infant, approximately twenty-nine to thirty-one weeks developed, had miraculously been delivered alive and was being given resuscitation and other aid by nurses when the doctor was informed of the situation. Without enquiring about the baby's condition, he ordered the nurses to render no assistance to her, but while he was returning to the hospital this order was disobeyed by the nurses. When the doctor appeared on the scene, the infant was still breathing. He was charged by another doctor, whom he summoned to the scene, with repeatedly strangling the baby until she finally ceased to breathe or exhibit a heartbeat.

The legal predicament of the doctor is clear, but is it consistent ? Under the Supreme Court decision in Roe v. Wade, ${ }^{2}$ a state can sanction third trimester abortions. California law does so, but also instructs that 'the rights to medical treatment of an infant prematurely born alive in the course of an abortion should be the same as the right of an infant of similar medical status prematurely born spontaneously.' 3 This places the doctor in a rather perplexing moral predicament. He is told that destroying a fetus in one spatiotemporal setting (inside the mother's body) is perfectly permissible while failing to assist it or actively intervening to terminate its life moments later in another setting constitutes murder.

\section{A philosopher's resolution}

One philosopher, Michael Tooley, offers a resolution to this dilemma which, while generating a consistent set of moral guidelines to the doctor, nevertheless creates an egregious moral precedent. Tooley attempts to justify both abortion and infanticide by contending that a fetus and an infant do not possess the properties required for an entity to have a 'serious right to life.'

... my argument has been that having a right to life $\vec{\varphi}$ supposes that one is capable of desiring to continue existing as a subject of experiences and other menta states. This, in turn, presupposes both that one hes the concept of such a continuing entity and that one believes that one is oneself such an entity. So an entity that lacks such a consciousness of itself as a continuing subject of mental states does not have a right to life. 4

Tooley anticipates that such a rule would only sanction the taking of a newborn's life within the first few weeks of existence. But as S I Benn ${ }^{5}$ has persuasively argued, it is doubtful whether even a $\overparen{D}$ two year old child has such a sophisticated concept of itself as an entity with 'a consciousness of itself as a continuing subject of mental states...' John $\delta$ Robertson ${ }^{6}$ has pointed out that Tooley is also subject to a 'thin edge of the wedge' problem in his 의 attempt to legitimate infanticide while proscribing $\rightarrow$ euthanasia. Having once possessed this concept of selfhood which entitles one to moral rights, Tooley $N$ maintains that a present vegetative state in which one no longer has that concept cannot invalidate $\tilde{O}$ one's claim to those rights. But why, Robertson $\mathbb{N}^{-}$ inquires, does past selfhood qualify as morally relevant while future selfhood, the position of the 0 fetus, does not; such a distinction is purely arbitrary. $\frac{}{\Phi}$

Other strategies have been employed by various ? philosophers which might offer a resolution to the doctors' dilemma.

I) Benn argues that, even if the fetus or infant $\frac{\Omega}{\square}$ were ruled out as persons ${ }^{7}$ there are consequentalist 
reasons of a rule utilitarian kind against infanticide. People will become callous toward human life thus jeopardising actual future people tomorrow by treating potential ones harshly today. Under such a rationale, however, it is difficult to see how all abortion would not have to be proscribed if infanticide is impermissible.

2) Controversy has centred around the status of the fetus; is it a person, a mere human being, or a potential person? Michael Tooley and Mary Anne Warren ${ }^{8}$ have attempted to discredit the potentiality principle, with Tooley arguing that if we would have no duty to refrain from killing kittens injected with a brain serum that would make them potential persons then we would have no similar duty towards fetuses, and Warren alleging that a merely potential person (non-sentient stuff) cannot be wronged.

Others have just as vehemently defended the potentiality principle. $\mathrm{R} M \mathrm{Hare}$, for example, argues that fetuses as potential people do have a right to non-interference under a Golden Rule moral principle:

If we are glad that nobody terminated the pregnancy that resulted in our birth, then we are enjoined not ceteris paribus, to terminate any pregnancy which will result in the birth of a person having a life like ours. ${ }^{9}$

Hare disparages Tooley's kitten example as based purely on intuitionism and not a sufficient refutation of the potentiality principle.

3) It is no wonder, then, that other philosophers have declared the question of the morality of abortion to be insoluble. Roger Wertheimer ${ }^{10}$ concludes that the status of a fetus is not a question of fact, for everyone could agree on the facts and still dispute over the interpretation of the facts, and hence, the legitimacy of abortion. George Sher ${ }^{11}$ and Grant Cosby 12 basically concur in this evaluation, contending that moral rules are indeterminate in this case; i.e., there is no way to determine rationally whether protection should be based on genetic capacity or on a developed capacity for future valued states.

\section{Another view of the dilemma}

Perhaps, the latter group of analysts have despaired too soon, and another approach might prove less ambiguous or controverisal. We would like to examine the implications of a strategy adumbrated by Judith Jarvis Thomson in her paper, 'A defense of abortion.' 13 It is her contention that even if one were to concur with the anti-abortionists' thesis that a fetus is a person, it does not necessarily follow that the termination of a fetus is immoral if one also pursues the line of argument that maintains that a mother has a just prior claim to her body. If we leave temporarily in abeyance the question of the personhood of the fetus, and investigate the position $\frac{3}{d}$ that the mother has a right to her own body, we may $\propto$ discover grounds for resolving the doctors' dilemma. T) What is unsettling about Thomson's argument is her

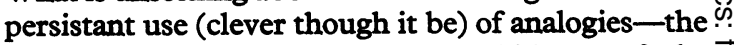
unwilling victim attached to the kidneys of the $\overrightarrow{\vec{F}}$ violinst is most memorable-for as Hare has argued, $\rightarrow$ conclusions drawn from such cases depend entirely upon the moral intuitions of the adjudicator. $\frac{\overline{\bar{N}}}{\bar{b}}$ Thomson's intuitions would certainly not be shared by the typical Catholic defender of abortion 0 nor anyone who held an extreme altruistic moral के ethic. Also, Thomson appears to compromise when $\vec{O}$ she declares abortion permissible for fourteen year $\overrightarrow{-}$ olds, but positively indecent for a woman in her $\vec{\sigma}$ seventh month who wants an abortion simply to avoid the nusiance of postponing a trip abroad.

\section{Self-ownership}

Let us assume ${ }^{14}$ that human beings possess a right to the ownership of their own bodies, $i e$, a right to the use and disposition of their persons. How can $\vec{c}$ this be applied to the case at hand, the resolution of the doctors' dilemma ? First, let us look at the rights in question during the pregnancy of the host. ${ }^{15} 3$ Despite 'slippery-slope' arguments to the contrary, we will argue that a fairly decisive demarcation $\vec{\bullet}$ point can be ascertained factually and, what is moge $c$ important, morally defended. Thus, the argum from self-ownership will proceed in two stages:

I) Before viability of the fetus,

2) After viability.

\section{BEFORE VIABILITY OF THE FETUS}

Before viability, the contrasting assumptions that the fetus is or is not now a person or a potential person and if either of these, whether it has rights, will yield the same conclusion in either case Regardless of how these disputes are resolved, the determination will be morally irrelevant on a self-ownership moral criterion. If we grant the assumption that the fetus is a potential person and, therefore has rights of self-ownership, what follows? This right cannot make a difference while it is inside the body of an unwilling host. If it is a person (or a potential person) and it is there in her body against her will, then it has no right to be there. If it is not a person (or potential person), then the conclusion is identical. If the woman owns her own body, the use and disposition of it is subject to hero control and her control alone. The fetus if unwanted ${ }^{\omega}$ by the woman, is an intruder, a virtual parasite. It cannot be wronged by being detached from the host because it has no right to be there in the first place

It is also irrelevant that the fetus did not perform a conscious act of aggression in placing itself insides the host's womb, for the fetus, for whatever reasond occupies, and therefore intrudes upon, the person of the host without her consent. If it is removed and 
thereby dies, it has not been killed by the host. Rather, it has died in the process of being justifiably ejected from the host's body. The intention of the host was to justifiably remove the fetus, not to kill it. If it is alleged, in response, that the mother had consensually 'placed' the child in her womb by volitionally participating in an act that could possibly lead to conception and is thereby obligated to keep it there, then the following must be considered. When one owns a thing (whether material property or future claims to performance of an act) that ownership involves the right to change one's mind concerning how one wishes to employ that property. If I decide that I no longer wish to grow corn on my farm but instead begin to grow barley, that is perfectly within my rights.

Abortion is undeniably a case which has consequences of much greater severity than the farm example. But does the severity of the consequences alter the rights? On a self-ownership principle it certainly does not. If the fetus is ejected before viability it will cease to exist, just as Judith Thomson's violinist attached to your kidneys will die if you disconnect him. It is not murder in either case, because in both instances the entitlement of the host to her body implies a right to remove presently unwanted entities from a location within it or from a parasitism upon it. The rights of the infant or the violinist to their own persons do not extend to the bodies of others. As a farm's crops may be removed by its owner, so unwanted persons may be ejected from one's body.

The farm example, it may be alleged, is illegitimately analogised to the present case which involves the relationship of two parties. It might be objected that in having used her body so as to engender a new life, the host thereby signified agreement to carry that life to full term. But, the basis for such a tacit agreement is altogether too thin. First, such an agreement might not have even remotely been a part of her intention in engaging in a sexual act, and second, the other party to the agreement, the as yet unconceived fetus, does not exist at this stage as even a potential person. If contracts can only be made with persons (or potential persons) then such an agreement cannot have taken place.

\section{AFTER VIABILITY}

But what about the period after the fetus becomes viable, does this change anything ? After viability, at roughly twenty-eight weeks, according to present medical technology, the fetus can survive independently of the host given the usual life-support facilities that are afforded to other premature babies. If the fetus were to be aborted in a manner that held the possibility of producing a live infant rather than a corspe, it might survive just as any spontaneously born premature baby might live. Now, the relevance of its status as a bearer of a right to its person is significant, as its life must be taken from it by an active and purposive assault upon its

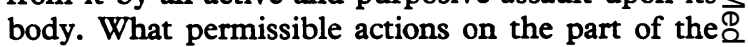
woman and her physician may be taken in this newm context? It would seem that a woman who desired $\overrightarrow{\bar{F}}$. an abortion after viability would still have a right to? her own body and could eject the intruder.

But, are we left with a 'double effect' problem of one person's rights (the host's) conflicting with? another person's rights (the viable fetus) ? Is there a $\frac{\bar{c}}{\bar{c}}$ way to resolve this apparent antagonism ?

The mother owns her own body; therefore, she $\stackrel{\mathbb{D}}{\circ}$ can remove the fetus from it, but can she do so by employing a process that would directly cause its $\vec{\circ}$ death? No. For then she would be intentionally: causing the death of a being who might have the $\vec{\omega}$ same right to life as any infant or adult person. To? desire the death of a viable fetus, then, might not be abortion (legitimate self-defence of your body) buter rather, murder, the forcible taking of another $\omega$ person's life. But, does a viable fetus have the right $\vec{\omega}_{\tilde{W}}$ of self-ownership that we concede to the mother? One consideration suggests that it does. Given that it ${ }_{-}$ can survive independently at the moment of its $\vec{C}$ ejection it can develop into an entity with the qualities in virtue of which we call its mother $a \mathbb{\Phi}$ person. Hence, there are grounds for asserting its $\vec{z}$ claim to be a potential person which would be inappropriate if applied to its nonviable predecessor. $\vec{\omega}$

Thus, the Supreme Court erred in Roe v. Wade when it permitted states to allow abortions that result in death for the fetus after it has attainề을 viability. Abortion ought to be permitted in the last trimester of pregnancy only if it involves a procedure that would induce early labour with the $\frac{0}{\mathrm{D}}$ intent of producing a live infant.

\section{The mother's responsibilities}

Now, what would be the mother's responsibilities: towards such an infant? Clearly, she would have none because she has rejected all obligations. As: Thomson argued, one becomes obligated to a baby by not aborting it, by not giving it up for adoption and by taking it home. This might loosely be $\frac{O}{3}$ termed a 'tacit contract'. Our unwilling host has not fulfilled these criteria. What, then, becomes of the? ejected infant?

There are two possible resolutions to this question。 The first derives from the minimal assumption that $N$ there is a universal right to one's person which requires duties of non-interference and forbearance from injurious behaviour on the part of others. $\omega$ However, if one believes that there is a secondary right to the supports of life, one would have in addition to this right of non-interference a right to assistance.

On the right-to-one's person theory alone the baby could not be actively interfered with or injured or killed. But neither would anyone have an? obligation to sustain its life. It theoretically could $\mathbb{Q}$ 
fend for itself. In fact, it would die unless Good Samaritans, childless couples, right-to-life groups, or other interested parties voluntarily consented to provide for its care. Under current conditions, this would present no discernible problem for many babies. Problems might arise, however, with severely defective babies or with infants of mixed or minority parentage. In either case, individuals would be confronted with the decision of whether and how to expend their resources upon abandoned children.

On the view that there is an additional right to the supports of life, someone-the mother, society, the hospital-would have an obligation to sustain the life of the infant. That is, someone could be compelled to support the child. This would involve denying to some person(s) the full right to use and dispose of his/her own baby at all times. Then, we have the old 'double effect' problem coming back to haunt us; the right to assistance of the baby $v s$. the right of self-ownership of the unwilling people compelled to sustain its life.

The positive right-to-life (which we have called assistance rights) position presents thorny problems which can be avoided by the negative right-to-life (which we have called the rights-to-one's person) interpretation. The negative right-to-life scenario seems preferable on grounds of logical consistency and parsimony. That is, such a right could be compossibly exercised by all persons. In practice, given the premium placed upon babies in our society, the right-to-one's person theory would secure the same results as the alternative for healthy infants. Notice that even the assistance rights position does not avoid the difficult problem of defective infants; someone has to make decisions about the weight of an unwanted child's claims to limited recources under a positive right-to-life principle. Some authority must decide how these scare medical goods ought to be allocated. Should Saint Mary's Hospital be permitted to buy an additional kidney dialysis machine or should they spend their funds on performing life-saving operations on spina bifida babies or mongoloids? Government officials, hospital boards, doctorssomeone will be making these unpleasant decisions. It appears, then, that both interpretations of the right-to-life have the inescapable problem of assessing the needs of these children in order to decide on the appropriate disperson of, in the first case, private resources, and in the second case public resources. It should be emphasised that on a negative right-to-life principle no one has a duty to make a decision as to whether an infant shall live or die, whereas on the positive principle some person(s) or social institution does have such an obligation.

\section{Conclusion}

How does the right to self-ownership strategy resolve the doctors' diemma? The position of a doctor seems much clearer, now. When he aborts a live infant he cannot strangle it. He cannot, morally, perform a third trimester abortion that will intentionally kill the fetus. He has no obligation to personally provide for the continued support of the infant, but if others are willing to supply such aid he should treat the baby in the same manner as he would the product of any live delivery. Therefore, given our self-ownership assumption, there is no morally permissible infanticide or destruction of a viable fetus.

It is undoubtedly true that as medical science के advances, the stage at which a fetus could be viable $\vec{\circ}$ will tend to gradually recede towards the point of conception. This presents no new problems for this argument; we would simply have to reappraise the point at which only abortions that aim at the production of live infants would be required. Thus, what we have demonstrated is that given an assumption of self-ownership abortion is always a right of a woman unwillingly pregnant, but after the viability of the fetus such a procedure can only be applied if it aims at the delivery of a live infant. This approach provides certain advantages because it satisfies pro-abortionists by acknowledging the imprescriptible right of a woman to an abortion, while it grants the anti-abortionists at least part of their case in that fetuses that can survive independently cannot be deprived of that opportunity.

\section{References and notes}

${ }^{1}$ The case referred to is that of Dr William Waddill in the California Superior Court, Orange County. In 1975, Dr Kenneth Edelin was charged in the Massachusetts Courts of attempting to smother a fetus while in the womb and failing to save it after it was born. He was convicted by the trial court, and the conviction was overturned by the appeals court. In the Waddill case, the trial ended in a hung jury after the judge, during deliberation of the jury, redefined death as brain death. A second trial has been requested by the prosecution.

${ }^{2}$ Roe v Wade (410 United States I13, 935 Supreme Court 705, r973).

${ }^{3}$ Bok, S, (1976). Case study: the unwanted child: caring for a fetus born alive after an abortion, Hastings Center Report, 6, 10-15.

"Tooley, M, (1974). Abortion and infanticide. In The rights and wrongs of abortion ed. Marshall, Cohen, Nagel \& Scanton p 64. Princeton, Princeton University Press.

${ }^{5}$ Benn, S I, (1973). Abortion, infanticide and respect for persons. In The problem of abortion ed. Feinberg, $J$ Belmont, California, Wadsworth

${ }^{6}$ Robertson, J A, (1977). Involuntary euthanasia of defective newborns: a legal analysis. In Ethical $c$ issues in modern medicine ed. Hunt, $\mathrm{R} \&$ Arras, $\mathrm{J}$ pp 206-209. Palo Alto, Mayfield.

${ }^{7}$ For Benn, a person is defined as an entity aware of himself as an agent, as making decisions that make a difference to the way the world goes, as having projects, and as capable of assessing his own performance as important or unimportant. 
${ }^{8}$ Warren, M A, (1977). Do potential people have moral rights? Canadian journal of philosophy, 7, 2 pp 275-284.

${ }^{2} \mathrm{Hare}, \mathrm{H} \mathrm{M}$, (1975). Abortion and the golden rule, Philosophy and public affairs, 4, 3 p 208.

${ }^{10}$ Wertheimer, $R$, (1974). Understanding the abortion argument. In The rights and wrongs of abortion op cit.

11Sher, G, (1977) Hare, abortion and the goldren rule, Philosophy and public affairs, 6, pp 185-190.

${ }^{12}$ Cosby, G, (1978). Abortion, an unresolved moral problem, Dialogue, 17, pp ro6-1 I2.

${ }^{13}$ Thomson, J J, (1974). A defense of abortion. In The rights and wrongs of abortion op. cit.

${ }^{17} \mathrm{We}$ have simply assumed a right to self-ownership in human beings without proof. Such a proof would be beyond the scope of a paper of this kind. Assuming that a proof, or failing that, a presumption in favour of a right to self-ownership could be demonstrated, what follows for settling the abortion-infanticide question and the doctor's dilemma? This is the strategy we have employed.

${ }^{15}$ 'Mother' appears to be a loaded term, therefore we have substituted the more neutral sounding term 'host'.

\section{Commentary}

\section{Gerard J Hughes SJ Department of Philosophy, Heythrop College, University of London}

The paper by Jeffrey and Ellen Paul is a useful and stimulating one. It is useful in that it provides a convenient survey of some of the recent literature and relates it to practical issues facing American (and presumably not only American) doctors and nurses: and stimulating, because it offers a somewhat new philosophical argument, which deserves a philosophical reply. Limitations of space permit me to do no more than indicate the general lines along which I would want to challenge it. I offer these remarks as presenting at least prima facie difficulties against his position which would need to be overcome before it could be regarded as acceptable.

One crucial area of ambiguity concerns the aim of the paper. Is it aiming simply at clearing up a practical difficulty left unresolved by the present state of American law ? Or is it undertaking the much more difficult task of giving a philosophically satisfactory account of the responsibilities of the medical professions in the area of abortion? The announced aim is the first of these; and they are careful to present their conclusions as hypothetical only, contingent on the acceptance of a particular premiss about the rights of ownership. This premiss is recommended to us, apparently, on no other grounds except that it would give a rationale for solving a legal dilemma. I suspect, though, that they are much more ambitious. Why, for example, is the position of the American doctor described as a dilemma? On their own account, the legal duties of $\frac{1}{d}$ doctors in various circumstances are all clear enough; the criticism seems rather to be that Roe v. Wade in conjunction with other decisions leads to a position which is philosophically arbitrary and morally incoherent. The optimistic tone of their conclusions, and their hope that they will provide an acceptable compromise between extreme positions suggest that they are claiming not merely legal clarity but a philosophical and moral success. It is this claim which I wish to challenge.

The term 'ownership' as the Pauls use it is far from clear. One might, for example, accept that a person owns his own body. And if one further accepted that a fetus were part of one's body, it might then follow that one would have a right to remove it, as one might have a right to have one's hair cut or one's nose shortened. Even on these assumptions, however, it would not follow that one could do just what one liked; it is not in general true that one can do what one likes with one's property. I cannot, for example, burn down my house if to do so would endanger the lives or property of others. Of course, it is no part of the Pauls' case that the fetus is part of the body of the mother (or, as they significantly prefer, 'host'). Possibly, then, they wish rather to speak of a right to privacy (a concept mentioned in the judgment given in Roe v. Wade) ? This would $\vec{\varphi}$ explain their speaking of the fetus as an intrudees co and a 'virtual parasite'. But of course it would be less. plausible for them to have framed their case in termis of privacy, since privacy is surely too weak a notion to justify overriding any rights the fetus may have and in particular it would not follow that the mother would have the right to abort whether or not the fetus has rights, as they conclude. Once it is conceded that the fetus has rights, and that those rights might conflict with the mother's, it cannot simply be asserted without proof that 'the intention of the host is justifiably to remove the fetus, not to kill it'. That is just what must be proved. The Pauls will either have to invoke just the kind of version of the principle of double effect that is rightly discredited in moral theology, or they will have to appeal to the distinction between the rights of viable and those of non-viable fetuses which is one of the weakest parts of the legislation they are criticising. ${ }^{1}$

I am also unconvinced by their other suggestion that we adopt the weaker ownership assumption to o deal with the rights of aborted living infants. I am N quite unconvinced that the mother has no respon- N sibilities just because she has refused to accept any. $O$ Though I can quite appreciate the difficulty involved in deciding who should be responsible for an infant $\stackrel{\circ}{\circ}$ whose mother refuses to care for it, I do not see that $\stackrel{Ð}{\rightleftharpoons}$ this issue can be solved by a bland denial that any such responsibility exists. The Pauls are right to 0 point out that to accept a stronger hypothesis about $\mathbb{\mathbb { D }}$ 'assistance rights' would not solve all the problems. No, but it would locate them properly, and would 